\title{
BMJ Open Protocol for a systematic review of economic analyses of nosocomial infection prevention and control interventions in OECD hospitals
}

\author{
Eric Nguemeleu Tchouaket (D) , ${ }^{1}$ Idrissa Beogo, ${ }^{2}$ Drissa Sia, ${ }^{3}$ Kelley Kilpatrick (D) , ${ }^{4}$ \\ Catherine Séguin, ${ }^{5}$ Aurelie Baillot, ${ }^{3}$ Mahmoud Nadar, ${ }^{3}$ Natasha Parisien, ${ }^{6}$ \\ Sandra Boivin ${ }^{7}$
}

To cite: Tchouaket EN, Beogo I, Sia D, et al. Protocol for a systematic review of economic analyses of nosocomial infection prevention and control interventions in OECD hospitals. BMJ Open 2020;10:e037765. doi:10.1136/ bmjopen-2020-037765

- Prepublication history and additional material for this paper are available online. To view these files, please visit the journal online (http://dx.doi. org/10.1136/bmjopen-2020037765).

Received 18 February 2020 Revised 02 June 2020 Accepted 08 June 2020

D) Check for updates

(c) Author(s) (or their employer(s)) 2020. Re-use permitted under CC BY-NC. No commercial re-use. See rights and permissions. Published by BMJ.

For numbered affiliations see end of article.

\section{Correspondence to} Professor Eric Nguemeleu Tchouaket; eric.tchouaket@uqo.ca

\section{ABSTRACT}

Background Nosocomial infections (NIs) are associated with extra treatment costs, medical complications, reduction of quality of life and mortality. This systematic review intends to consolidate the evidence on the economic evaluation of four clinical best practices (CBPs) related to NI prevention and control interventions: hand hygiene, hygiene and sanitation, admission screening and basic and additional precautions. It will measure the return on investment of these CBPs.

Methods and analysis Electronic searches will be conducted on MEDLINE, CINAHL, EMBASE, Cochrane, Web of Science and JSTOR. OpenGrey will also be consulted for articles from 2000 to 2018, published in English or French. The population includes studies undertaken in medical or surgical units of hospitals of the Organisation for Economic Co-operation and Development countries. Studies will report the prevention and control of Clostridium difficile-associated diarrhoea, methicillin-resistant Staphylococcus aureus, vancomycin-resistant enterococci and carbapenem-resistant Gram-negative bacilli. Interventions evaluating any of the four CBPs will be included. The design of articles will fall within randomised clinical trials, quasi-experimental, case-control, cohort, longitudinal and cross-sectional studies. Outcomes will include incremental cost-effectiveness ratio, incremental cost per quality-adjusted life-year, incremental cost per disability-adjusted life year and the incremental cost-benefit ratio, net costs and net cost savings. Two authors will independently screen studies, extract data and assess risk of bias using the Scottish Intercollegiate Guidelines, the Drummond Economic Evaluation criteria and the Cochrane criteria for Systematic Reviews of Interventions. Consolidated Health Economic Evaluation Reporting Standards will be used for data extraction. All values will be adjusted to Canadian dollars (\$C) indexed to 2019 using the discount rates $(3 \%, 5 \%$ and $8 \%)$ for sensitivity analyses. This review will demonstrate the effectiveness of the CBPs in prevention and control of Nls. Decision-makers will thus have evidence to facilitate sound decision-making according to the financial gains generated.

Ethics and dissemination The results of this systematic review will be published in a peer-reviewed journal and presented at a relevant scientific conference. Ethical approval is not required because the data we will use do not include individual patient data.
Strengths and limitations of this study

- Previously unaddressed cost-effectiveness and cost benefit of four clinical best practices (hand hygiene, hygiene and sanitation, screening, basic and additional precautions) associated with nosocomial infection prevention and control are evaluated.

- While other studies focus on a single disease-causing pathogen, this review will consider the clinical best practices related to the prevention and control of four pathogens: Clostridium difficile-associated diarrhoea, methicillin-resistant Staphylococcus aureus, vancomycin-resistant enterococci and carbapenem-resistant Gram-negative bacilli.

- Articles will be scrutinised by two reviewers for inter-rater reliability, and later assessed for quality including the Scottish Intercollegiate Guidelines, the Economic Evaluation criteria developed by Drummond et al and Cochrane criteria for systematic review.

- Only the Organisation for Economic Co-operation and Development countries will be considered, limiting the generalisability of these findings to other nations.

- Paediatric patient populations will not be considered; thus, this review will provide an estimate, but not true cost of nosocomial infection control for a paediatric population.

\section{INTRODUCTION}

Nosocomial infections (NI) or heathcareassociated infections have been defined by the Centers for Disease Control and Prevention as 'a localised or systemic condition resulting from an adverse reaction to the presence of an infectious agent(s) or its toxin(s)'. ${ }^{1}$ This condition must develop $>48$ hours after admission to the healthcare setting, and there must be no previous evidence of the infection. NIs are a serious topical public health problem experienced around the world and are associated with extra treatment costs, complications, 
reduction of quality of life and mortality. ${ }^{2-4}$ Since 2004, in Québec, Canada, there have been mandatory monitoring programmes for the prevention and control of four pathogens that cause NIs: Clostridium difficile-associated diarrhoea (CDAD), methicillin-resistant Staphylococcus aureus (MRSA), vancomycin-resistant enterococci (VRE) and carbapenemresistant Gram-negative bacilli (CRGNB) ${ }^{5-8}$ These programmes are generally based on four clinical best practices (CBPs) related to NI prevention and control (NIPC) interventions: hand hygiene, hygiene and sanitation, admission screening and basic and additional precautions. ${ }^{9}$

There are some literature reviews related to the impacts of NIPC interventions. Most of them are generally related to the economic burden of NIs. ${ }^{10-12}$ The systematic review conducted by Arefian $e t$ al provided an economic analysis of the prevention and control of NI in hospitals around the world. ${ }^{2}$ It dealt with the prevention and control of falls, urinary tract infections, surgical site infections, blood infections and pneumonia in medical, surgical, paediatric and intensive care units. However, this systematic review did not focus directly on the prevention and control of the four organisms mentioned above (CDAD, MRSA, VRE and CRGNB). Furthermore, among the interventions analysed, additional precautions (eg, isolation of patients) and hygiene and sanitation were not considered. Other systematic reviews of the literature have focused on the effectiveness of the prevention and control of a single NI. ${ }^{13-15}$ Unfortunately, they are $>7$ years old. On the other hand, an information audit of NIPC programmes was also conducted by Stone et al. ${ }^{16}$ This audit highlighted the efficiency of the prevention and control of the four organisms by taking into account the different forms of economic analysis: cost-minimisation analysis (CMA); cost-effectiveness analysis (CEA); costutility analysis (CUA) and cost-benefit analysis (CBA). Unfortunately, this audit review, which was not a systematic review, did not assess the quality or risk of bias of the articles included in the study. It also did not assess the effectiveness of the four CBPs (hand hygiene, hygiene and sanitation of surfaces and equipment, admission screening and additional precautions) simultaneously.

To the best of our knowledge, faced with gaps in the literature, it seems appropriate to conduct a systematic review of the literature to consolidate the evidence on economic evaluation of the four CBPs related to NIPC interventions. This review will allow our team to measure the return on investment of these practices for the prevention and control of the four most common NIs in hospitals in Canada. Furthermore, this systematic review will analyse the effectiveness of the interventions through five economic analysis approaches: CMA, CEA, CUA, CBA and cost-consequences analysis (CCA).

\section{METHODS}

\section{Theoretical framework}

This study is based on the infection control intervention framework developed by Resar $e t a t^{\theta}$ at the Institute for
Healthcare Improvement in the USA, which defines a set of CBPs, or 'bundles', each of which consists of three to five evidence-based practices. These practices ensure that all healthcare professionals can provide safe care to their patients. This intervention framework supported the implementation, in Canadian and Quebec healthcare institutions, of infection prevention and control strategies as well as the creation of Canadian ${ }^{6}$ and Quebec ${ }^{517}$ safe care campaigns. According to the Public Health Agency of Canada, best practices focused on NIPC would reduce the risk of contracting some NIs to nearly zero. ${ }^{18}$ The four actions that will be considered in this study across all bundles are: (1) hand hygiene; (2) hygiene and sanitation of surfaces and equipment; (3) admission screening of patients with, or who are at risk of infection, in accordance with the healthcare facility's protocols and (4) the application of basic and additional precautions. The NIPC theoretical framework for this study highlighting the four CBPs associated with reduction of rates of infection is presented in figure 1 .

\section{Hand hygiene}

Hand hygiene refers to the washing and disinfection of hands, wrists and forearms using water, soap, hydroalcoholic solutions or alcoholic antiseptic solutions. This action begins with wetting the hands and continues until they are completely dry. ${ }^{19}$ WHO estimates that hand hygiene could help reduce healthcare-associated infections by between $30 \%$ and $70 \% .^{20}$

\section{Hygiene and sanitation of surfaces and equipment}

In 2005, the Au coin report, entitled D'abord, ne pas nuire (first, do no harm), stressed the importance of cleanliness and sanitation as a basic measure for infection prevention and control. ${ }^{21}$ Neglecting the regular preventive cleaning and disinfection of surfaces and equipment results in a reservoir for the proliferation of microorganisms. Hygiene and sanitation must be carried out with appropriate frequency (one or more times per day) depending on the prevalence of infection at the site. ${ }^{22} 23$

\section{Screening on admission of patients who are carriers or who are considered at-risk}

Screening is the systematic testing of persons for a previously undetected NI condition or a potential carrier. Screening techniques differ depending on the type of organisms of concern which have the potential to cause an NI in the patient or be transferred to others. In general, it consists of making a clinical diagnosis and performing laboratory analyses. Any patient who is currently hospitalised or has been previously hospitalised is considered at-risk if he or she presents with signs and symptoms related to an infection. Those patients who present without any signs or symptoms are considered colonised or potential carriers. Analyses of faeces and blood, nasal smears, laboratory tests and blood cultures may be used to detect pathogens according to predefined surveillance protocols for each of the NIs, in symptomatic 


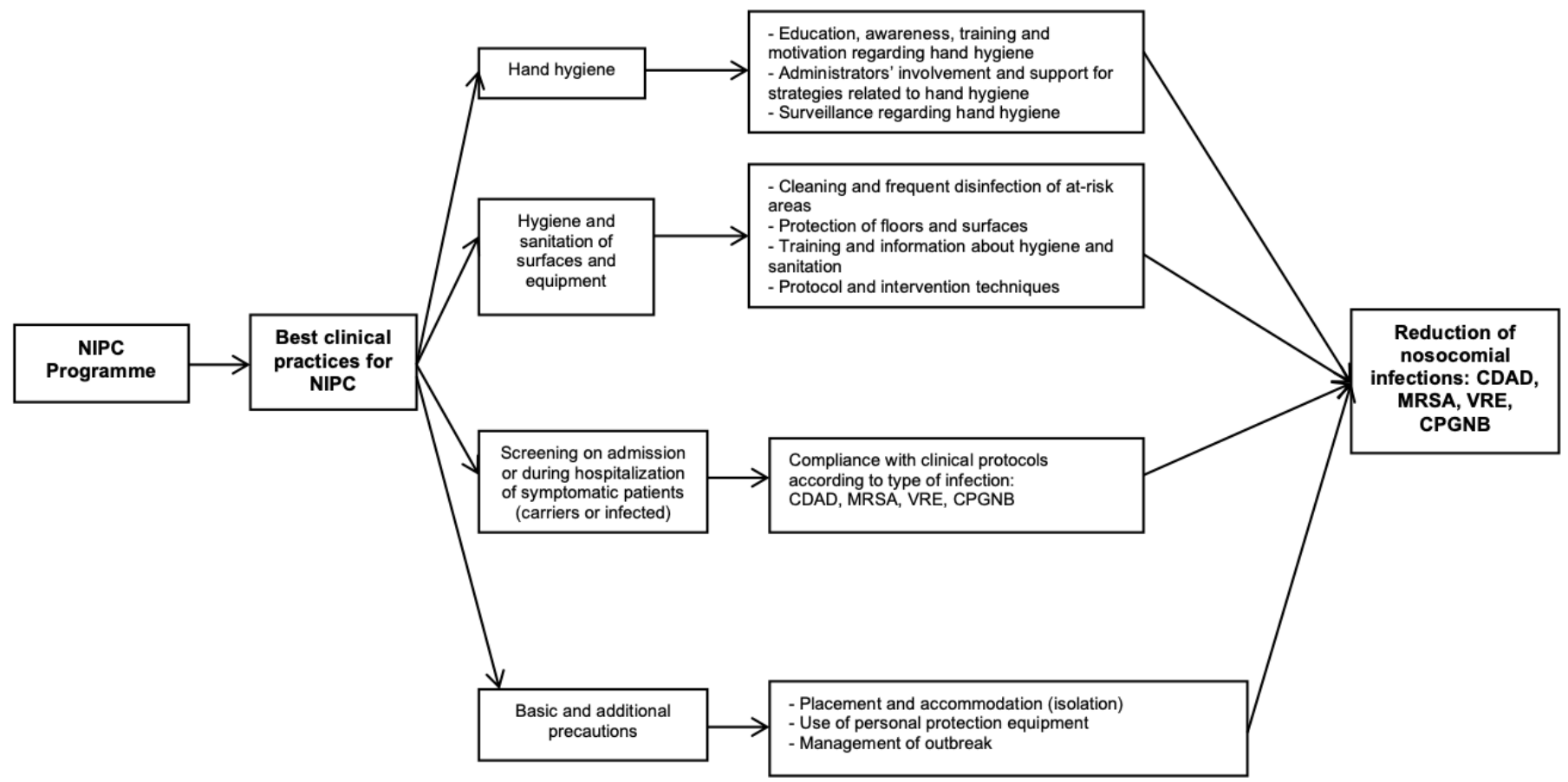

Figure 1 Nosocomial infection prevention and control framework based on clinical best practices. CDAD, Clostridium difficileassociated diarrhoea; CRGNB, carbapenem-resistant Gram-negative bacilli; MRSA, methicillin-resistant Staphylococcus aureus; NIPC, nosocomial infection prevention and control; VRE, vancomycin-resistant enterococci.

or even asymptomatic patients. ${ }^{24-27} \mathrm{~A}$ bacterial strain is considered resistant if it meets certain clinical diagnostic criteria in conjunction with minimum inhibitory concentration tests used to determine the most appropriate antibiotics. $^{25}$

\section{Additional precautions}

In addition to the three above-mentioned basic practices, additional precautions must be taken when an NI is reported. While these depend on the infection detected, they include, but are not limited to, isolation measures and the application of contact precautions with patients who are carriers or infected. ${ }^{8}$ In the event that a major outbreak of an NI is declared, best clinical practices must be intensively applied, and additional meetings and resources are added over the course of its duration. ${ }^{28}$

\section{Economic analysis and research questions}

Before embarking on an economic analysis, it is important to clarify that the interpretation of economic studies must consider three elements: the analytical perspective, the time horizon and other factors influencing cost, all the while taking into account the patient's prior condition. ${ }^{29}$ The analytical perspective-patient, hospital or societal-determines the choice of costs to include in the calculations. For example, from a hospital perspective, medical costs will not include patient-related costs after discharge or costs related to lost productivity due to hospitalisation. The time horizon sets the time frame within which medical costs are measured. Other factors influencing the costs of care are the stage and severity of disease, comorbidities, risk factors, admitting diagnosis and length of stay. ${ }^{29} 30$
There are several approaches to economic analysis of intervention efficiency: CMA, CEA, CUA, CBA and CCA. ${ }^{31-34}$ The first three are based on comparing interventions. A CMA assumes identical outcomes and compares only intervention costs. A CEA assesses the differential cost-effectiveness ratio representing the incremental cost, divided by number of life-years gained. A CUA calculates the differential cost-utility ratio indicating the additional cost required for health-related quality of life (qualityadjusted life-year (QALY)) improvements. In a CBA, costs and benefits are measured in monetary units. The difference between economic benefits and costs in terms of net gains or losses is estimated. In this approach, an examined intervention will be compared against the status quo to determine its return on investment or profitability. ${ }^{30}$ Finally, a CCA is based on a tabular presentation of costs and consequences. Once the cost valuation has been completed, a list is drawn up of all possible intervention outcomes and the choice can be made to value certain potential outcomes. ${ }^{31}$

Conducting an economic analysis of NIPC therefore involves examining issues of quality management, prevention and care safety. Thus, as Finkler $(1993,1996)$ stated, the cost of quality management takes into account both the cost of investing in preventive measures and the cost of quality failures or problems experienced. ${ }^{35} 36$ The author suggests a certain level of quality can be achieved by investing in prevention. As such, there is a threshold, called the optimum, beyond which prevention could increase quality. Therefore, according to Finkler's model, the economic analysis of a NIPC programme using CBPs requires that the following questions be asked: 
Table 1 Population, Interventions, Comparators and designs, Outcomes design

\begin{tabular}{|c|c|}
\hline \multicolumn{2}{|l|}{ Population } \\
\hline Geographic area & OECD \\
\hline Establishment & Hospitals, acute care or short-term care facilities \\
\hline Care unit & Medical and surgical \\
\hline Patients & $\begin{array}{l}\text { Hospitalised }>48 \text { hours and }<30 \text { days } \\
\text { Excluded: children }\end{array}$ \\
\hline Infections studied & CDAD and MDROs (MRSA, VRE, CPGNB) \\
\hline \multicolumn{2}{|l|}{ Interventions } \\
\hline Clinical best practices (CBPs)* & Hand hygiene; hygiene and sanitation; screening; additional precautions \\
\hline Type of design and comparators & $\begin{array}{l}\text { Randomised clinical trial, quasi-experimental study, longitudinal study, case-control } \\
\text { study, cohort study (prospective or retrospective) }\end{array}$ \\
\hline $\begin{array}{l}\text { Outcomes depending on the type of } \\
\text { economic evaluation }\end{array}$ & $\begin{array}{l}\text { Costs estimates of CBPs, incremental cost-effectiveness ratio, incremental cost per } \\
\text { quality-adjusted life-year, incremental cost per disability-adjusted life-year and the } \\
\text { incremental cost-benefit ratio, net costs and net cost savings }\end{array}$ \\
\hline
\end{tabular}

i. What are the costs of NIs related to poor quality?

ii. What is the cost of investing in prevention through CBPs in NIPC?

iii. What is the optimal break-even point for measuring return on investment when comparing prevention intervention costs against potential benefits?

\section{Eligibility criteria}

The inclusion and exclusion criteria for the studies will be based on the Population, Interventions, Comparators and designs, Outcomes design, summarised in table 1.

\section{Type of population (P)}

The study will include studies related to the prevention and control of the most commonly monitored pathogens causing NIs in Quebec hospitals since 2004: CDADs and the three multidrug-resistant organisms: MRSA, VRE and CRGNB. Furthermore, acute-care wards (medicine and surgery) with the highest numbers of hospitalised patients aged 18 years and over will be considered. Finally, the population of the Organisation for Economic Co-operation and Development (OECD) countries will be targeted. Paediatric as well as long-term care settings will be excluded.

\section{Type of interventions (I)}

The interventions targeted by this review will be based on the study's theoretical NIPC framework (figure 1). The four major types of intervention (hand hygiene, hygiene and sanitation, screening and additional precautions) related to CBPs in NIPC will be analysed. Studies that only investigated other prevention measures will be excluded.

Type of comparators or designs

In regard to comparators and designs, this review will include: randomised clinical trials, quasi-experimental, case-control, cohort (retrospective and prospective), longitudinal and cross-sectional studies. We will consider all studies that use control groups, either as standard of care or relative levels of compliance. We will also include all studies that measure the effectiveness of NIPC campaigns, especially as it might concern compliance. However, we will focus on studies that provide a measure of economic evaluation of various NIPC practices. Reviews and studies, technological assessments, purely clinical studies, studies based solely on mathematical and statistical modelling will be excluded.

Type of outcomes or intended results $(0)$

Outcomes or intended results $(\mathrm{O})$ will cover the quantitative studies using CMA, CEA, CUA, CBA and CCA, as well as those combining any of these types of analyses. We will consider healthcare facilities for the analytical frame and 1 year as the time horizon. Studies that only assess the costs and cost-effectiveness of any of the four CBPs will also be included.

Cost outcomes will be reported in terms of: (i) cost estimates of hand hygiene, hygiene and sanitation, admission screening and basic and additional precautions (measures of cost will include average estimated cost of human and material resources, as well as products used for each CBP) and (ii) measure of cost-effectiveness reported as the incremental cost-effectiveness ratio, incremental cost per QALY, incremental cost per disability-adjusted life year, incremental cost-benefit ratio and net costs.

\section{Data sources and research strategy}

This systematic review was registered with the Research Registry of systematic reviews/Meta-analyses (researchregistry5355: https://www.researchregistry. com/browse-the-registry\#home/). It will be conducted in accordance with the recommendations of Preferred Reporting Items for Systematic Review and Meta-analysis 
Table 2 CINAHL search strategy, to be modified as needed for the four other databases

\begin{tabular}{|c|c|}
\hline No. & Queries \\
\hline 1 & $\begin{array}{l}\text { 'cross infection'.sh. OR clostridium difficile.sh. OR vancomycin resistant enterococci.sh. OR VRE.ti. or VRE. } \\
\text { ab. or ERV.ti. or ERV.ab. OR (Enteroc*.ti. or Enteroc*.ab.) AND (resistant.ti. or resistant.ab.) AND (vancomycin. } \\
\text { ti. or vancomycin.ab.) OR methicillin resistant staphylococcus aureus.sh. OR Carbap*.ti. or Carbap*.ab. OR } \\
\text { (Staphylococcus.ti. or Staphylococcus.ab.) AND (aureus.ti. or aureus.ab.) AND (methicillin.ti. or methicillin.ab.) }\end{array}$ \\
\hline 2 & (Staphylococcus.ti. or Staphylococcus.ab.) AND (aureus.ti. or aureus.ab.) AND (methicillin.ti. or methicillin.ab.) \\
\hline 3 & VRE.ti. or VRE.ab. or ERV.ti. or ERV.ab. \\
\hline 5 & Carbap*.ti. or Carbap*.ab. \\
\hline 6 & (Bacil*.ti. or Bacil*.ab.) AND (gram.ti. or gram.ab.) AND (neg*.ti. or neg*.ab.) \\
\hline 7 & $\begin{array}{l}\text { methicillin resistant staphylococcus aureus.sh. OR vancomycin resistant enterococci.sh. OR clostridium difficile.sh. } \\
\text { OR "cross infection".sh. }\end{array}$ \\
\hline 8 & 1 OR 2 OR 3 OR 4 OR 5 OR 6 OR 7 \\
\hline 10 & ('cost allocation' or 'cost benefit analysis' or 'cost control' or 'cost savings' or 'costs and cost analysis').sh. \\
\hline 11 & 9 OR 10 \\
\hline 12 & 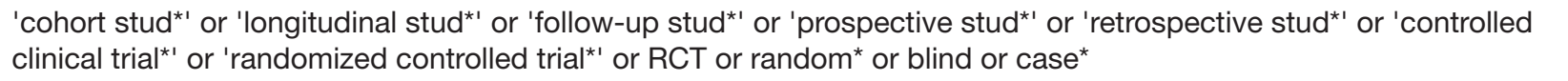 \\
\hline 13 & $\begin{array}{l}\text { cohort studies.sh. OR longitudinal studies.sh. OR follow up studies.sh. OR prospective studies.sh. OR retrospective } \\
\text { studies.sh. OR randomized controlled trial.sh. OR controlled clinical trial.sh. OR case control studies.sh. }\end{array}$ \\
\hline 14 & 12 OR 13 \\
\hline 15 & $\begin{array}{l}\text { (clean* or control or prevention or screen* or wash or protect* or isolation or sanitation or hand* or aseptic* or } \\
\text { intervent }^{\star} \text { or program }{ }^{\star} \text { or strateg* or hygiene*).ab,ti }\end{array}$ \\
\hline
\end{tabular}

Protocols $^{37}$ (see online supplementary file 1). All specifications for elements related to the construction of the flow diagram will be explicitly presented. Articles will be selected from the scientific literature. The following six electronic bibliographical databases will be considered on iterative exploratory searches: MEDLINE via Ovid, CINAHL, EMBASE, Cochrane, Web of Science and JSTOR. Grey literature, namely Cordis and OpenGrey, will be added. Additionally, two NIPC programme officers and coauthors will contribute to the validation by determining the keywords specific to NIPC. Only scientific articles written in English or French and published between 2010 and 2019 will be included in the study. The databases will be queried using descriptors or thesauri with the logical operators 'AND' and 'OR'. We developed the search strategy in collaboration with an experienced librarian (CS) and the research strategies to be tested (table 2) have already been defined during the working meetings of the co-investigators.

Citations will be imported into Rayyan ${ }^{38}$ following which article selection will be undertaken by two reviewers working independently. In order to reinforce the uniformity, all authors will screen the same $10 \%$ of the titles and the abstracts.

\section{Selection process}

The research strategy will be applied by the librarian (CS) at the Saint-Jérôme campus of the Université du Québec en Outaouais to select scientific articles from the databases and prepare the EndNote bibliographic database. In the first round of selection, two independent reviewers (ET, IB) will screen all of the titles and abstracts of the selected articles. Duplicates will be identified and removed. We built an algorithm (figure 2) that will be used by each reviewer to perform an initial screening of articles using predefined eligibility criteria. An article will be retained if both independent reviewers consider it eligible. If one of the reviewers rejects an article, a third reviewer (another coauthor) will analyse the article title and abstract and make a final decision. An article will be rejected if at least two of the three reviewers consider it ineligible. In the final round, all articles screened from the reading of title and abstracts will be read in their entirety. Those that meet our criteria will be retained.

\section{Data extraction}

Regarding the data extraction, a consensually framed Excel spreadsheet based on Consolidated Health Economic 
First round screening algorithm

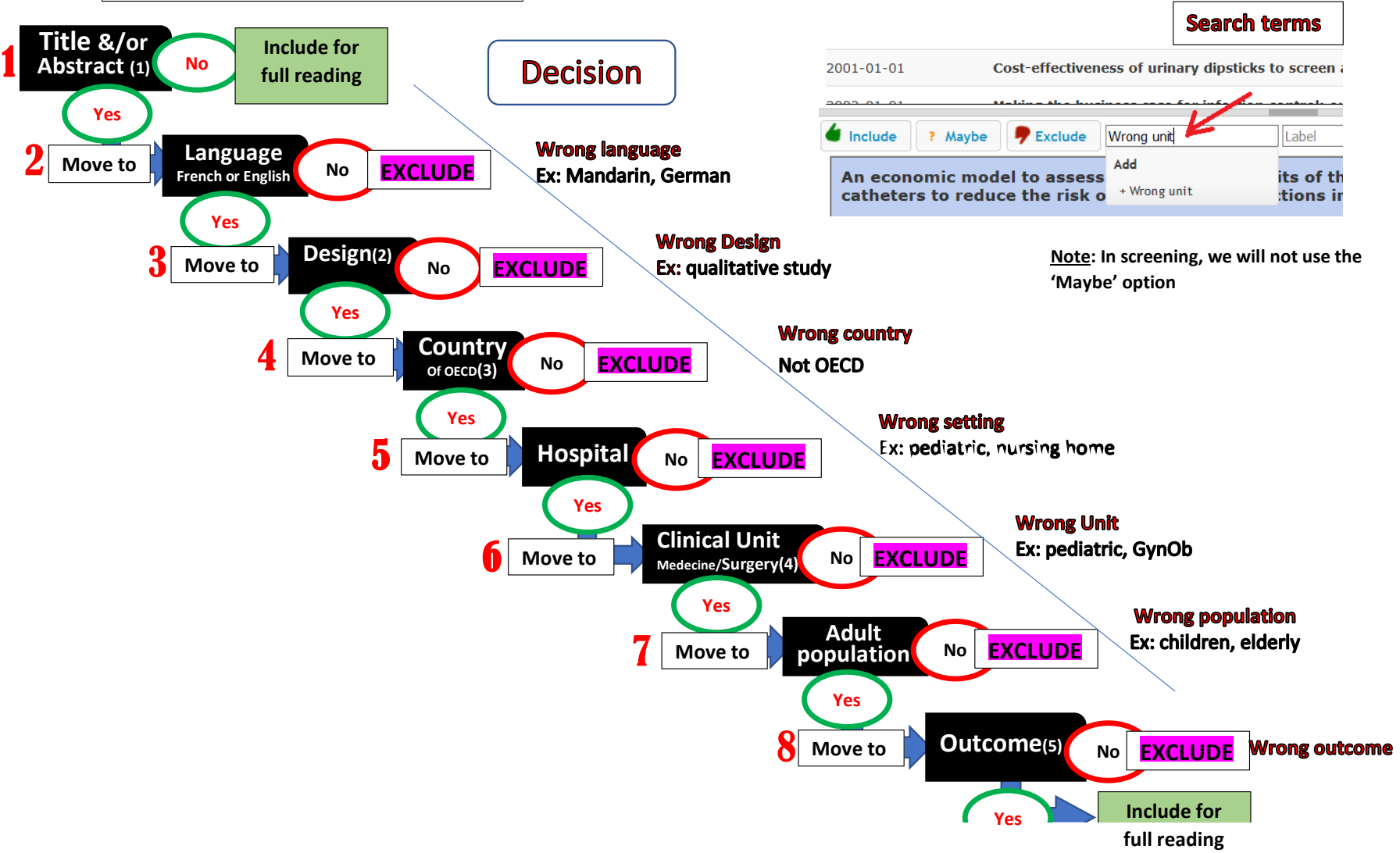

Figure 2 Screening algorithm. ${ }^{1}$ The reference has or does not have a TITLE and/or an ABSTRACT. ${ }^{2}$ Design: controlled clinical trial or RCT or (Cohort or Longitudinal or Follow-up or Prospective or Case or Blinded or Retrospective) studies or crosssectional studies. EXCLUDED: qualitative studies, literature reviews or studies based solely on mathematical and statistical modelling: ${ }^{3}$ OECD countries: OECD OR Australia OR Austria OR Belgium OR Canada OR Chile OR The Czech Republic OR Denmark OR Estonia OR Finland OR France OR Germany OR Greece OR Hungary OR Iceland OR Ireland OR Israel OR Italy OR Japan OR Korea OR Latvia OR Lithuania OR Luxembourg OR Mexico OR Netherlands OR Holland OR New Zealand OR USA or Norway OR Poland OR Portugal OR Slovak Republic OR Slovenia OR Spain OR US or Sweden OR Switzerland United Kingdom OR England OR UK OR United States of America. ${ }^{4}$ Clinical setting: acute care, medicine, surgery. EXCLUDED: nursing home, long-term care and paediatric ward. ${ }^{5}$ Outcomes: incremental cost-effectiveness ratio, incremental cost per quality-adjusted lifeyear, incremental cost per disability-adjusted life-year and the incremental cost-benefit ratio, net costs and net cost savings. EXCLUDED: studies assessing technology or studies purely clinically oriented.

Evaluation Reporting Standards ${ }^{39}$ will be built to extract the following information: authors, year of publication, title and abstract, objective of the study, country, type of clinical unit, design, type of economic evaluation, sample size, population size, currency and adjustment year, time horizon, outcomes related to incremental cost and funding sources. The extraction will be made by one reviewer (IB) and the principal investigator (ENT) will validate. If the article requires technical or professional expertise, two PCI programme specialists (SB and $\mathrm{NP}$ ) will assess the content and confirm the validation.

Risk of bias assessment or assessment of the quality of the articles

All articles that satisfy the inclusion criteria will be analysed. Based on the approach used by Arefina $e t a l^{2}$ the selected articles will be analysed using three tools:

i. First, the audit guidelines for economic evaluation studies recommended by the SIGN. ${ }^{40}$ ii. Second, the Economic Evaluation criteria developed by Drummond $e t a \vec{l}^{00}$ to assess the quality of the articles; these criteria are commonly used in health economic evaluation and were used in previous research we conducted. ${ }^{33}$ Based on the 10 criteria of this scale, the studies will also be classified into three groups according to their quality: high quality ( 8 or more of the 10 criteria present); medium quality (between 5 and 7 criteria present) and low quality (below 5 criteria).

iii. Third, the Cochrane criteria ${ }^{41}$ for economic evaluation will be used to ensure compliance with the standards of the Cochrane Handbook for Systematic Reviews of Interventions. It will also be used to assess the risk of bias in individual articles. As with the extraction of articles, two reviewers will independently assess the quality of the articles. If a consensus is not reached, a third reviewer will arbitrate. 


\section{Data analysis and aggregation of results}

For each type of intervention, costs, incidence reduction of NIs owing to the intervention, cost-effectiveness ratios, cost-utility ratios and cost-benefit ratios will be classified in results tables. The year of calculation and the currency used will also be indicated. Based on the exchange rate, all currencies will be converted to Canadian dollars (\$C) of the same benchmark year. Using the discount rates of $3 \%, 5 \%$ and $8 \%$ recommended by Montmarquette and Scott, ${ }^{42}$ the costs will be converted to CAD 2019. The median values of cost outcomes (in terms of reducing the incidence of an NI), and incremental ratios (cost-effectiveness, cost-utility and cost-benefit) will be estimated for each discount rate. Sensitivity analyses will be carried out on the median values, indicating the maximum and minimum values of the outcomes. This approach was used in a study conducted by Tchouaket $e t$ $a l .{ }^{43}$ Finally, we will use the Grading of Recommendations, Assessment, Development and Evaluations guidelines ${ }^{44}$ to analyse the robustness of the suggested recommendations in relation to the efficiency of CBPs in NIPC. In cases of missing information on inflation adjustment, we plan to first contact the corresponding author. If this is not successful, we will assume that the costs were adjusted to the last year of the data collection in the study.

\section{Ethics and dissemination}

The results of this systematic review will be published in a peer-reviewed journal and presented at a relevant scientific conference. Ethical approval is not required because the data we will use do not include individual patient data. However, this systematic review is included in the protocol of the research programme entitled 'Analyse économique de la prévention et contrôle des infections nosocomiales'. This programme has been accepted by the Research Ethics Committee of the Université du Québec en Outaouais.

\section{DISCUSSION}

Critically appraising and synthesising evidence from a body of NIPC literature across diverse healthcare systems, populations and intervention methodologies carries an inherent limitation in the interpretation of findings. To help address this challenge, we will assess studies using the above-mentioned quality guidelines in order to group studies by level of quality, and all findings will be interpreted with caution.

Despite the fact that this paper takes into account a limited number of NIPC interventions (four), this study will be useful for decision-making. It will provide information on implementation costs and financial profits to be invested in preventive measures related to CBPs to prevent the four most commonly monitored organisms that cause NIs. It will inform the international scientific literature on the cost of investing in CBPs related to NIPC and particularly on the efficiency of NIPC-related CBPs. The results will therefore be useful for comparison between OECD countries in terms of the four clinical best practices related to NIPC. This review may in turn promote the investment in NIPC programmes. It may also increase compliance in these practices, giving healthcare providers and policy makers evidence that can encourage the effective application of infection control guidelines.

\section{Patient and public involvement}

This systematic review was undertaken without patient involvement. Patients were not invited to comment on the study protocol design and were not consulted as to how this work may inform patient relevant outcomes or how a patient might interpret results. Patients were not invited to contribute to the writing nor the editing of this manuscript; however, a representative of the Québec public health network (NP) and two clinical nurses working with patients (SB, KK) are among the coauthors. The results of this work will be disseminated to the public and to the healthcare professional networks involved in this project via conferences, publications and presentations.

Author affiliations

${ }^{1}$ Sciences Infirmières, Université du Québec en Outaouais, Gatineau, Quebec, Canada

${ }^{2}$ School of Nursing and Health, Université de Saint-Boniface, Winnipeg, Manitoba, Canada

${ }^{3}$ Nursing, Université du Québec en Outaouais, Gatineau, Quebec, Canada

${ }^{4}$ Nursing, McGill University, Montreal, Quebec, Canada

${ }^{5}$ Universite du Quebec en Outaouais, Gatineau, Quebec, Canada

${ }^{6}$ Institut national de santé publique du Québec, Quebec, Quebec, Canada

${ }^{7}$ CISSS des Laurentides, Saint-Jerome, Quebec, Canada

Acknowledgements The authors would like to thank the FRQS for its financial support. The authors would also like to thank all the staff and managers at the public health department of the Laurentian Region and the nursing department of the Saguenay-Lac-Saint-Jean region.

Contributors ET, SB, CS, NP, IB, KK, DS, AB and MN made substantial contributions to study conception and design for this research protocol. All authors were involved in drafting and making revisions to critical intellectual content in the manuscript. All authors gave final approval of the version to be published.

Funding This research project has been funded by the Fonds de Recherche du Québec-Santé (FRQS) from 1 April 2017 to 31 March 2021, grant number 35124.

Disclaimer The funding bodies played no role in developing the study nor in writing the manuscript.

Competing interests ET received a Junior 1 researcher award from the FRQS.

Patient consent for publication Not required.

Provenance and peer review Not commissioned; externally peer reviewed.

Open access This is an open access article distributed in accordance with the Creative Commons Attribution Non Commercial (CC BY-NC 4.0) license, which permits others to distribute, remix, adapt, build upon this work non-commercially, and license their derivative works on different terms, provided the original work is properly cited, appropriate credit is given, any changes made indicated, and the use is non-commercial. See: http://creativecommons.org/licenses/by-nc/4.0/.

\section{ORCID iDs}

Eric Nguemeleu Tchouaket http://orcid.org/0000-0002-4309-0478

Kelley Kilpatrick http://orcid.org/0000-0003-2137-6560

\section{REFERENCES}

1 Horan TC, Andrus M, Dudeck MA. CDC/NHSN surveillance definition of health care-associated infection and criteria for specific 
types of infections in the acute care setting. Am J Infect Control 2008;36:309-32.

2 Arefian $\mathrm{H}$, Hagel S, Heublein S, et al. Extra length of stay and costs because of health care-associated infections at a German university hospital. Am J Infect Control 2016;44:160-6.

3 Bohlouli B, Jackson T, Tonelli M, et al. Health care costs associated with Hospital acquired complications in patients with chronic kidney disease. BMC Nephrol 2017;18:375.

4 Cassini A, Plachouras D, Eckmanns T, et al. Burden of six healthcareassociated infections on European population health: estimating incidence-based Disability-Adjusted life years through a population Prevalence-Based modelling study. PLoS Med 2016;13:e1002150.

5 Laberge A, Carignan A, Galarneau LA, et al. L'hygiène et autres mesures de prévention des infections associées aux bactéries multirésistantes: document synthèse. Montreal, QC: Gouvernement du Québec, 2014.

6 Canadian Patient Safety Institute. New approach to controlling superbugs. Safer healthcare now! Campaign. Ottawa, ON: CPSI, 2010.

7 Institut national de santé publique du Québec. Campagne québécoise des soins sécuritaires - volet prévention et contrôle des infections. Montreal, QC: Gouvernement du Québec, 2014.

8 Public Health Agency of Canada. Routine practices and additional precautions for preventing the transmission of infection in healthcare settings. Ottawa, ON: Government of Canada, 2013.

9 Resar R, Griffin FA, Haraden C, et al. Using care bundles to improve health care quality. IHI innovation series white paper. Cambridge, MA: Institute for Healthcare Improvement, 2012.

10 Zhen X, Lundborg CS, Sun X, et al. Economic burden of antibiotic resistance in ESKAPE organisms: a systematic review. Antimicrob Resist Infect Control 2019;8:137.

11 Zimlichman E, Henderson D, Tamir O, et al. Health Care-Associated infections: a meta-analysis of costs and financial impact on the US health care system. JAMA Intern Med 2013;9763:E2-8.

12 Ghantoji SS, Sail K, Lairson DR, et al. Economic healthcare costs of Clostridium difficile infection: a systematic review. J Hosp Infect 2010;74:309-18.

13 Agence d'évaluation des technologies et des modes d'intervention en santé. Évaluation du rapport coûts-bénéfices de la prévention et du contrôle des infections nosocomiales SARM dans les centres hospitaliers de soins généraux et spécialisés. Gouvernement du Québec: Agence d'évaluation des technologies et des modes d'intervention en santé, 2010

14 Stone PW, Larson E, Kawar LN. A systematic audit of economic evidence linking nosocomial infections and infection control interventions: 1990-2000. Am J Infect Control 2002;30:145-52.

15 Farbman L, Avni T, Rubinovitch B, et al. Cost-benefit of infection control interventions targeting methicillin-resistant Staphylococcus aureus in hospitals: systematic review. Clin Microbiol Infect 2013;19:E582-93.

16 Stone PW, Braccia D, Larson E. Systematic review of economic analyses of health care-associated infections. Am J Infect Control 2005;33:501-9.

17 Institut national de la santé publique du Québec. Surveillance provinciale des diarrhées Clostridium difficile au Québec: protocole. Montreal, QC: Gouvernement du Québec, 2018.

18 Public Health Agency of Canada. The chief public health officer's report on the state of public health in Canada 2013 - infectious disease - the never-ending threat. Ottawa, ON, 2013.

19 Pittet $D$, Widmer A. Hygiène des mains: nouvelles recommandations. Swiss-NOSO 2001:8:25-32.

20 World Health Organization. WHO guidelines on hand hygiene in health care, first global patient safety challenge clean care is safer care, 2009. Available: https://apps.who.int/iris/bitstream/handle/ 10665/44102/9789241597906_eng.pdf

21 Comité d'examen sur la prévention et le contrôle des infections nosocomiales. D'abord, ne pas nuire. Les infections nosocomiales au Québec, un problème majeur de santé, une priorité. Gouvernement du Québec, Ministère de la Santé et des Services sociaux, 2005.
22 Groupe de travail en hygiène et salubrité. Guide de gestion intégrée de la qualité en hygiène et salubrité. Gouvernement du Québec, 2013.

23 Groupe Hygiène et salubrité au regard de la lutte aux infections nosocomiales. Lignes directrices en hygiène et salubrité: analyse et concertation. Québec, QC: Gouvernement du Québec, 2006.

24 Institut national de la santé publique du Québec. Surveillance des infections bacilles Gram négatif producteurs de carbapénémases au Québec: protocole. Montreal, QC: Gouvernement du Québec, 2017.

25 Institut national de la santé publique du Québec. Surveillance provinciale des bactériémies Staphylococcus au Québec: protocole. Montreal, QC: Gouvernement du Québec, 2018.

26 Institut national de la santé publique du Québec. Surveillance provinciale des infections entérocoque résistant la vancomycine au Québec: protocole. Montreal, QC: Gouvernement du Québec, 2018.

27 Institut national de la santé publique du Québec. Surveillance provinciale des bactériémies nosocomiales dans les centres hospitaliers de soins aigus du Québec: protocole. Montreal, QC: Gouvernement du Québec, 2018.

28 Comité sur les infections nosocomiales du Québec. Précisions sur la gestion d'une éclosion majeure de grippe saisonnière nosocomiale en milieux de soins: lignes directrices. Montreal, QC: Gouvernement du Québec, 2013.

29 Etchells E, Mittmann N, Koo M. The economics of patient safety in acute care. Ottawa, ON: Canadian Patient Safety Institute, 2012.

30 Drummond M, Sculpher MJ, Claxton K, et al. Methods for the economic evaluation of health care programmes. UK: Oxford University Press, 2015

31 Brousselle A, Lessard C. Economic evaluation to inform health care decision-making: promise, pitfalls and a proposal for an alternative path. Soc Sci Med 2011;72:832-9.

32 Institute of Medicine (US) Committee on Quality of Health Care in America. Crossing the quality chasm: a new health system for the 21st century. Washington (DC: National Academies Press (US), 2001.

33 Tchouaket E, Brousselle A. Using the results of economic evaluations of public health interventions: challenges and proposals. Can $J$ Program Eval 2013;28:43-66.

34 Tchouaket E, Brousselle A, Fansi A, et al. The economic value of Quebec's water fluoridation program. $Z$ Gesundh Wiss 2013;21:523-33.

35 Finkler SA. Total quality management: measuring costs of quality. Hosp Cost Manag Account 1993;5:1-6.

36 Finkler SA. Measuring the costs of quality. Hosp Cost Manag Account 1996;7:1-6.

37 Shamseer L, Moher D, Clarke M, et al. Preferred reporting items for systematic review and meta-analysis protocols (PRISMA-P) 2015: elaboration and explanation. BMJ 2015;349:97647.

38 Ouzzani M, Hammady H, Fedorowicz Z, et al. Rayyan-a web and mobile app for systematic reviews. Syst Rev 2016;5:210.

39 Husereau D, Drummond M, Petrou S, et al. Consolidated Health Economic Evaluation Reporting Standards (CHEERS)--explanation and elaboration: a report of the ISPOR Health Economic Evaluation Publication Guidelines Good Reporting Practices Task Force. Value Health 2013;16:231-50.

40 Scottish Intercollegiate Guidelines Network. Sign 50: a guideline developer's Handbook. Edinburgh: SIGN, 2015.

41 Higgins JPT, Thomas J, Chandler J, et al. Cochrane Handbook for systematic reviews of interventions (updated July 2019). 2019; version 6. Available: https://training.cochrane.org/handbook

42 Montmarquette C, Scott I. Taux d'actualisation pour l'évaluation des investissements publics au Québec. Montreal: Centre for Interuniversity Research and Analysis on Organizations (CIRANO), 2007.

43 Tchouaket E, Dubois C-A, D'Amour D. The economic burden of nurse-sensitive adverse events in 22 medical-surgical units: retrospective and matching analysis. J Adv Nurs 2017;73:1696-711.

44 Guyatt GH, Oxman AD, Schünemann HJ, et al. GRADE guidelines: a new series of articles in the Journal of clinical epidemiology. $J$ Clin Epidemiol 2011;64:380-2. 